ISSN: 0514-7336

DOI: http://dx.doi.org/10.14201/zephyrus201780175191

\title{
LA TESSERA LUSORIA DEL PUIG DEL CASTELL DE SAMALÚS (BARCELONA): ¿MÁS QUE FICHAS DE JUEGO?
}

\section{The tessera lusoria from Puig del Castell de Samalús (Barcelona): more than gaming tokens?}

\author{
Marc Guàrdia i LLOREnS \\ Arqueólogo. Muralles.cat, CLOTs. C/ Padilla, 7. 08480 L'Ametlla del Vallès (Barcelona). Correo-e: marcguardia@ \\ muralles.cat
}

Recepción: 6/11/2016; Revisión: 30/03/2017; Aceptación: 20/05/2017

\begin{abstract}
Resumen: En este trabajo presentamos una nueva tessera lusoria recuperada en el transcurso de las excavaciones arqueológicas en el yacimiento ibérico layetano del Puig del Castell de Samalús (Cànoves i Samalús, Barcelona). La pieza, obrada en hueso, presenta una inscripción en latín en ambas caras, en la que podemos leer el vocativo GVLO y el numeral IIII. Además de hacer una aproximación tipológica de la pieza, intentamos profundizar sobre el significado de su presencia en un contexto indígena, así como encuadrar su presencia en el marco del resto de estas fichas de juego localizadas en la provincia Citerior. A partir de la recopilación de aquellas tesserae lusoriae para las que conocemos su lugar preciso de hallazgo, definimos su foco de difusión e intentamos aproximarnos a una mejor comprensión del fenómeno. Pretendemos abordar la cuestión desde una lectura del marco en el que fueron utilizadas, proponiendo la adscripción al grupo de población al que posiblemente estas fichas de juego pudieron pertenecer.
\end{abstract}

Palabras clave: Lauro; Layetania; romanización; juegos romanos; Gulo.

AвSTRACt: In this paper we present a new tessera lusoria found in the Iberian site of Puig del Castell de Samalús (Cànoves i Samalús, Barcelona). The piece, made of bone, has a latin inscription on both sides, in wich we can read the vocative GVLO and numeral IIII. Beyond making a typological approach of the piece, we try to develop the meaning of their presence in an indigenous context and frame their presence within the rest of these gaming tokens located in the Citerior. We are incorporing new data, only through the collection of all tesserae lusoriae that we know its precise place of discovery. We will define its origin and try to approach to a better understanding of the phenomenon. We try to address the issue focusing on the context in which they were used, indicating the group these gaming tokens belonged.

Key words: Lauro; Layetania; Romanization; Ancient Roman games; Gulo.

\section{Introducción}

En los últimos años han salido a la luz diversos trabajos que han dado a conocer, de manera individualizada, nuevas tesserae lusoriae. También se ha publicado alguna síntesis que avanza respecto a la comprensión de este fenómeno, por ejemplo, el trabajo publicado en esta misma revista por Rodríguez Martín (2016). Queremos sumarnos a estas recientes novedades bibliográficas presentando un nuevo ejemplar de estas interesantes fichas de juego e intentando dar un enfoque distinto, 


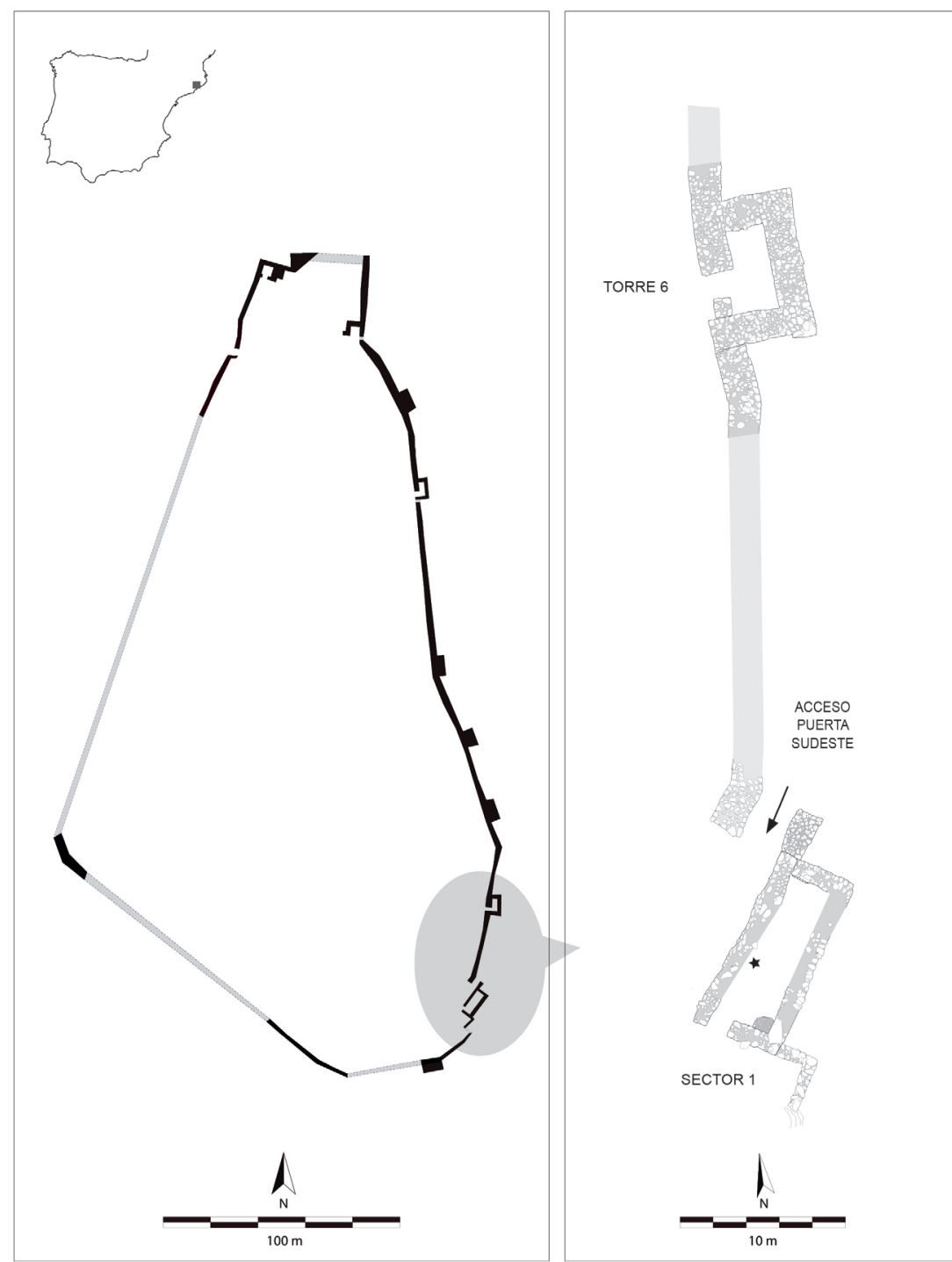

FIG. 1. Planta de la fortificación del Puig del Castell con ampliación de la zona de la Puerta Sudeste, indicando el lugar del hallazgo.

priorizando la interpretación arqueológica sobre la tipológica.

En este artículo presentamos el hallazgo de una tessera lusoria recuperada en los trabajos arqueológicos que se vienen desarrollando desde el año 2011 en el poblado ibérico del Puig del Castell de Samalús. Este yacimiento layetano, caracterizado por su imponente fortificación, presenta una ocupación que comprende desde mediados del s. v hasta mediados del I a. C. (Guàrdia, 2015). Recientemente también se ha desarrollado su más que probable identificación con la ciudad de Lauro, que emitía moneda con leyenda ibérica a su nombre, en base a una serie de diversos y sólidos argumentos (Guàrdia, 2016).

En el marco de la campaña de excavación de 2014 se intervino en la zona de uno de los accesos principales al conjunto fortificado, la Puerta Sudeste. Esta entrada se encuentra flanqueada por un amplio recinto que forma parte del complejo defensivo y que cabe relacionar con la protección de este acceso. Este espacio fue construido a lo largo del s. v a. C., pero en el iII a. C. se añade un muro paralelo a la muralla para reforzar y alargar el pasillo de acceso. Fue en este recinto (Fig. 1) donde se recuperó la pieza que presentamos.

Con el nombre de tesserae lusoriae se identifican unas pequeńas placas talladas mayoritariamente en hueso, de forma rectangular, que presentan un apéndice circular decorado y perforado. Su característica principal es que estas piezas presen$\tan$ una serie de inscripciones en ambos lados. En una de las caras se encuentra un calificativo que puede tener un valor injurioso o laudatorio, mientras que en la cara opuesta presenta un numeral. Hay una clara correspondencia entre los calificativos peyorativos y los números bajos, que van aumentando a medida que los epítetos son más propicios. Esta serie empieza consecutivamente del $I$ al $X X V$, conociendo solo un ejemplar del XXVII y finalizando en los números XXX y $X L$, relacionados con los vocablos más benevolentes. En algunos casos, después del numeral, encontramos una letra $A$ o el nexo formado por $A+L$. El uso de 
estas piezas se ha relacionado con un juego del que aún se nos escapa su exacto funcionamiento, aunque han sido propuestas distintas variantes. Sobre el tipo de juego existe ya una historiografía de la temática, nacida para responder al antiguo hallazgo del conjunto de Perugia (1887), en el que en el marco de la excavación de una tumba aparecieron 16 de estas piezas, que podríamos catalogar como la aproximación a lo que sería un lote entero para jugar. En esta primera referencia bibliográfica ya se logró encauzar la dinámica del juego con la observación de la correspondencia de los números bajos con los términos más soeces, y viceversa (Gamurrini, 1887: 398). Se propuso su identificación con el juego del ludus latrunculorum o el duodecim scriptorum, dos populares juegos de la antigüedad. Pocos años después, Huelsen (1896: 236), que realizó la primera gran compilación estudiando más de 80 tesserae lusoriae, aceptó la identificación con el ludus latrunculorum. En la actualidad esta identificación no es compartida por la mayoría de estudiosos, a la par que se han propuesto nuevas posibilidades del juego, como el hecho de sacar por azar las piezas de una bolsa (Balil, 1987), la adivinación mediante las fichas (Casagrande, 2012) o un tipo de juego de tablero parecido al de la oca (Campagna, 1995: 286). De todos modos, en lo relativo a la práctica del juego, hay una cuestión que ha pasado a menudo inadvertida. Al describir las piezas todos los investigadores han puesto de relieve los orificios de suspensión que se encuentran en las piezas, ubicados en la zona estrecha de contacto del apéndice circular con el cuerpo rectangular de la ficha, atravesándola por el lado más ancho. Muchos investigadores han relacionado los orificios practicados en las piezas para colgar, poder reunir y trasladar juntas las piezas. Pero el lugar en el que se han practicado estos orificios hace difícil ensartarlos todos y recoger de una manera funcional y práctica el lote que, como mínimo, veremos que sería de aproximadamente una veintena de piezas, puesto que el apéndice circular haría que chocasen unas con otras. Para lograr este objetivo hubiese sido más práctico, en lo relativo a su ejecución, realizar el agujero en el centro del apéndice circular, y no en un punto

(C) Universidad de Salamanca complicado por su estrechez implicando el riesgo de romper la pieza; a la vez también se reduciría el espacio que ocuparían las piezas juntas, ya que se replegarían sin el estorbo del apéndice. En alguna ocasión se ha expuesto que el modo de hacer el orificio está pensado para que, una vez colgadas, se puedan contemplar y leer los mensajes en las tesserae. Esta variable puede no ser baladí y tener cierta importancia en el juego, puesto que comportaría un tipo de práctica en la que sería necesario llevar la ficha encima, lo que descartaría la idea de requerir necesariamente un tablero, o sacarlas de una bolsa, por lo que los pequeños agujeros tendrían un carácter funcional en la práctica del juego (Cecchini, 2015: 68).

El objetivo del presente trabajo no es ofrecer un detallado estado de la cuestión ni del juego ni de la tipología de estas fichas, para ello nos remitimos al reciente trabajo de Rodríguez Martín, en el que se han recopilado más de 165 tesserae lusoriae, asociadas a 55 apelativos relacionados con los 30 numerales conocidos (Rodríguez Martín, 2016).

Sí que nos interesa, entre otros aspectos, anticipar la cuestión de su cronología. Conjuntos cerrados y amplios como los de Perugia y Vaste han permitido proponer la datación de estas piezas al final de la República, entre los ss. II y I a. C. El conjunto de Perugia se fechó de manera amplia a lo largo del s. II a. C. El caso de Vaste viene a confirmar, tanto la datación, como la composición del lote del juego, a tenor de haberse documentado, en esta ocasión, 17 fichas de juego, caso curiosamente análogo a las 16 de Perugia. El contexto ya no es funerario, sino que se localizaron en los estratos de amortización de una cisterna datada en el tercer cuarto del s. II a. C. (Campagna, 1995). El hecho de encontrar estas piezas juntas hace verosímil la lectura de que nos encontramos con un lote completo, o prácticamente, del juego. Hay otro caso que viene a confirmar esta interpretación, el del anfiteatro de Siracusa (Orsi, 1920), que ha pasado inadvertido en la bibliografía, y que ha sido recientemente rescatado del olvido (Colivicchi, 2007: 205; Baratta, 2015: 198, n. 13). En esta ocasión, el hallazgo en una fosa fue de 18 fichas, aunque su pésimo estado de conservación 


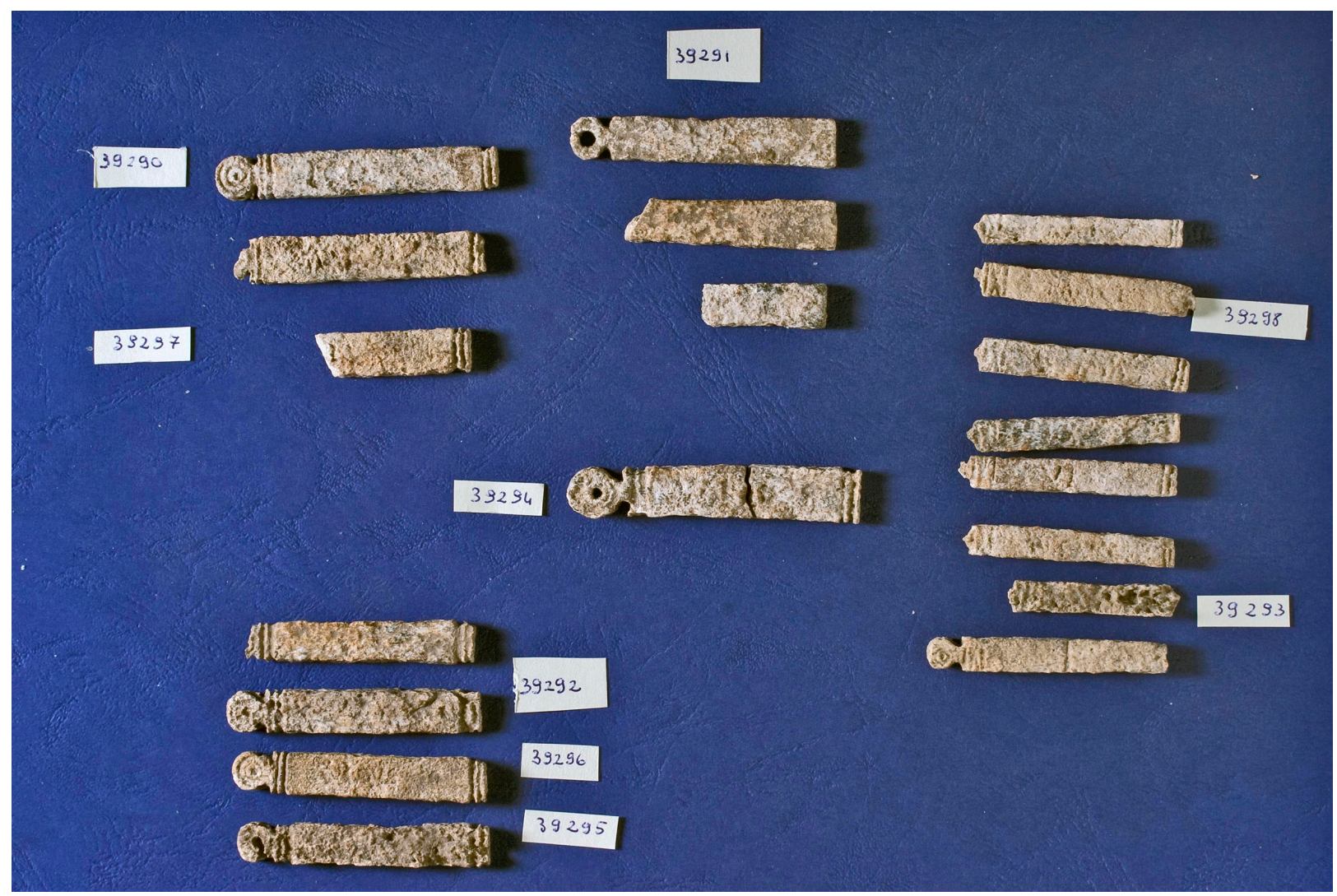

Fig. 2. Conjunto de tesserae lusoriae del hallazgo de Siracusa, en el Museo Archeologico Regionale Paolo Orsi de Siracusa (reproducido con autorización del Assessorato dei Beni Culturali e dell'Identità Siciliana).

solo ha permitido la lectura parcial de las tesserae ${ }^{1}$. Pero si nos fijamos en el conjunto de Sicilia (Fig. 2), conservado en el Museo Archeologico Regionale Paolo Orsi², observamos que está formado por 21 fragmentos que corresponden a un mínimo de 19 fichas de juego, tipológicamente muy homogéneas. Parece claro que el lote para jugar comprendía, pues, un conjunto que oscilaba en torno a la veintena de fichas. En lo que respecta a su datación, a

1 En la Fig. 5 presentamos las transcripciones tal y como Orsi las recogió en su trabajo. Se puede ver como la dificultad en su lectura proporcionó apelativos inéditos o parciales, aunque su resonancia y correspondencia con los numerales habituales hace suponer algunas equivalencias: NVGO, VAPIO, etc.

2 Agradecemos la amabilidad de la Dra. Manenti y la Dra. Musumeci, del Museo Archeologico Regionale Paolo Orsi de Siracusa, por habernos facilitado la información sobre ese conjunto. falta de poder documentar un contexto claro durante su excavación, no permitió aventurar ninguna fecha. En los casos en que sí se ha podido obtener información de orden cronológico la importancia radica no sólo en el hecho de contar con una datación sobre un conjunto cerrado, sino en dar luz a una cuestión que desafortunadamente no es habitual, puesto que en la mayoría de casos los objetos provienen de museos y colecciones, desprovistos de contexto, o son encontrados en niveles superficiales o funerarios claramente posteriores (cf. tabla de Fig. 5).

\section{La tessera lusoria del Puig del Castell de Samalús}

La ficha de juego que presentamos aquí es una pieza tallada en hueso, conservada parcialmente, con unas dimensiones de 3,2 x 0,9 × 0,4 cm (Fig. 3). 

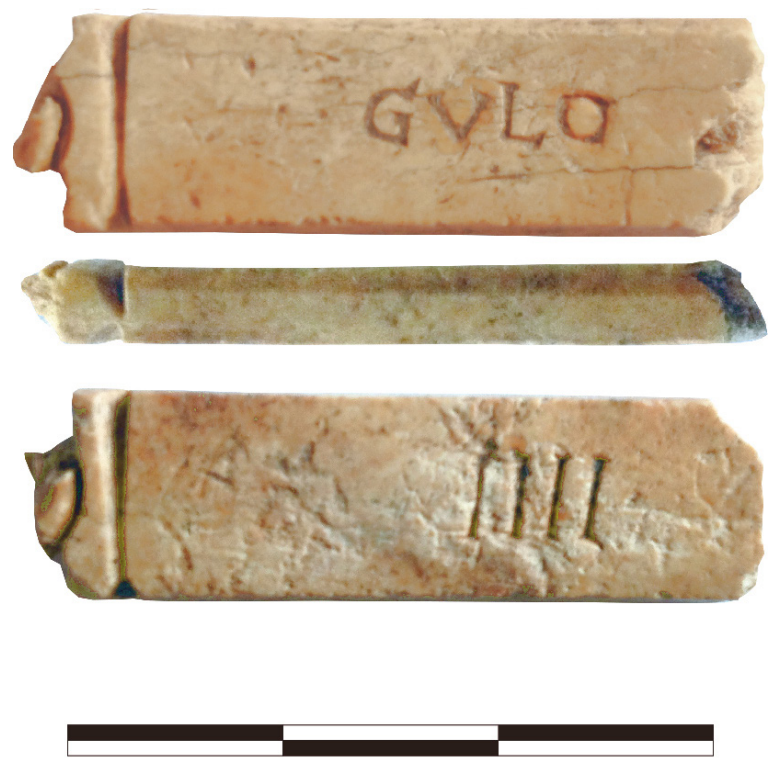

\section{$3 \mathrm{~cm}$}

FIg. 3. Tessera lusoria del Puig del Castell de Samalús.

En su extremo proximal solo se conserva parcialmente el apéndice circular, aunque se observa parte de su decoración incisa, así como la mitad del canal perforado que atravesaba el círculo por el lado ancho. En su cara principal presenta la inscripción GVLO, con la correspondencia en la cara opuesta con el numeral IIII. Ambas caras rectangulares presentan sendas incisiones a modo de decoración, cerca del apéndice. Nuestro ejemplar cabe datarlo en la fase republicana del yacimiento, en su último momento de ocupación, a lo largo de la primera mitad del s. I a. C. Como hemos mencionado anteriormente, la pieza fue recuperada en un ámbito de carácter defensivo-Sector 1, ue 61: nivel de amortización del pavimento- ocupado a lo largo de toda la vida del poblado. Como expondremos más adelante, la ubicación en la que se recuperó la ficha merece un comentario detallado.

La inscripción latina alude, en vocativo, al término gulo, gulonis (Banducci, 2015: 201), que tiene el significado de "glotón", en el sentido de alguien consagrado a comer y beber en exceso.

Nos puede sorprender la asociación de la voz GVLO con un numeral tan bajo, a tenor de diversos improperios que tienen correspondencia con números más altos. Cabría relacionarla con los valores tradicionales republicanos de la austeridad, entre los que la frugalidad sería uno de ellos. No son pocas las referencias en Cicerón a los malos hábitos en los banquetes, en los que se refiere, entre otros, a los excesos en la bebida y la comida ( $p$. ej.: Catilinarias 2,10).

De tesserae lusoriae con la voz GVLO conocíamos hasta ahora solo dos casos, siempre asociados al numeral IIII. El primero de ellos ya lo recogía Huelsen (1896: n. 16) en su compendio. Esta ficha se encuentra en la colección Guardabassi del Museo de Perugia, y recientemente se ha propuesto su probable origen en la ciudad de Chiusi (Banducci, 2015: 201). El segundo ejemplar corresponde a una pieza documentada en el interior de una tumba en la necrópolis de Gabii, que ha podido datarse en el s. I d. C. (Banducci, 2015) (Fig. 4).

Por otro lado, el número IIII no siempre ha tenido su par en el vocablo GVLO, sino que también se ha asociado a otras palabras de matriz igualmente negativa: EBRIOSE - borracho-, INFELIX -infeliz-, VAPIO - malcriado-y PERIVRE ${ }^{3}$.

Formalmente los tres ejemplares son coincidentes en su tipología, aunque hay pequeñas variaciones. En los dos ejemplares de la península itálica el campo epigráfico está enmarcado a ambos lados con incisiones, mientras que en el caso del Puig del Castell solo encontramos la incisión en el lado izquierdo de ambas caras. No debemos leer esta particularidad como una anomalía o una mala copia indígena, puesto que es una característica análoga al conjunto recuperado en Vaste (Campagna, 1995).

3 No consideramos aquí la correlación de FACETE - de resonancia positiva- y el numeral IIII expuesta recientemente por Rodríguez Martín (2016: fig. 6) siguiendo el ejemplar 14 del lote de Perugia, en la que en la tabla de Huelsen (1896: 228,14) se consideran los cuatro trazos oblicuos como un numeral, cuando estos trazos significan que hay un problema de lectura. Este extremo aún se puede constatar en la actualidad en la que se evidencia la nula conservación de la cara con el numeral de este mismo ejemplar (Casagrande, 2012). Las otras tesserae conocidas de FACETE tienen correspondencia con los números XXV-Pompeya, Paestum y otra de procedencia desconocida- y con el número $X I$ -Roma-, alejados del IIII. 
1
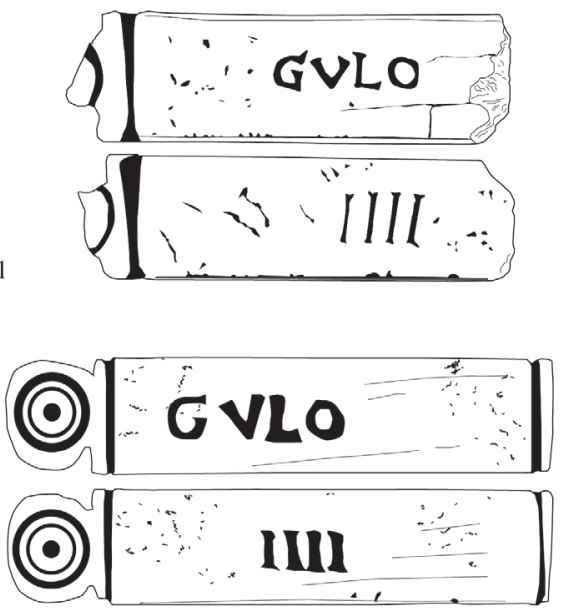

2
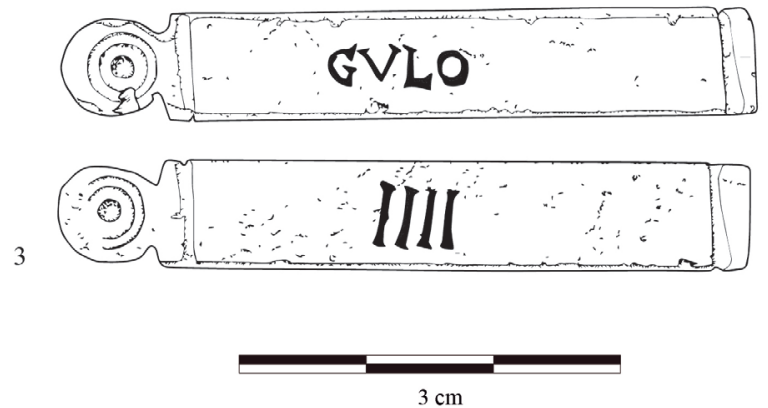

FIG. 4. Tesserae con inscripción GVLO y numeral IIII: 1) Puig del Castell de Samalús, Barcelona; 2) Chiusi, Museo de Perugia (en base a la fotografía de Banducci 2015); 3) Gabii (Banducci, 2015).

Tipológicamente las tesserae lusoriae están bien definidas, aunque encontramos ciertas diferencias, no ya en el módulo, sino en algunas características decorativas. Los lotes de Perugia, Vaste y Siracusa-de 16,17 y 19 piezas respectivamente- nos muestran cómo cada uno de estos conjuntos es homogéneo internamente a nivel tipológico, pero son ligeramente distintos entre ellos, indicándonos que la producción ha sido concebida en lotes enteros para el juego (Banducci, 2015: 204).

\section{Distribución e interpretación de los datos de los hallazgos}

Para poder realizar una aproximación contextualizada a la presencia de las tesserae lusoriae es necesario abordar la cuestión sobre la base de su cuantificación. En este tipo de recopilaciones es esencial poder discriminar sobre qué número de tesserae conocemos el lugar donde fueron encontradas. Del grado de confianza de la información dependerá la calidad y representatividad de la muestra, por lo que debemos ser restrictivos en la inclusión de hallazgos en la lista resultante. Para confeccionar este grupo hemos empezado por las que Huelsen recopila explicitando claramente su procedencia $-\mathrm{y}$ desestimando las otras-, y hemos ido añadiendo las que aparecen en otras compilaciones, novedades recientes o elementos dispersos en la bibliografía y que habían pasado desapercibidos (Fig. 5). Igualmente, no se han incorporado al corpus aquellas piezas que por razones tipológicas dudamos de su clara identificación con tesserae lusoriae, y que quizás deban incorporarse en otra tipología de fichas de jue$\mathrm{go}^{4}$. No obstante, somos conscientes del peligro que atañe en lo que respecta a la identificación del lugar de hallazgo para las piezas publicadas más antiguas, debido a que algunas proceden de colecciones privadas y adquisiciones y podemos legítimamente dudar sobre la procedencia adjudicada 5 . Aun habiendo

4 Por razones tipológicas y morfológicas no incorporamos las 2 piezas de Tarragona (Mayer y Rodà, 1988: 9.3.2 y 9.3.3), la de la necrópolis ibicenca del Puig dels Molins (Mayer y Rodà, 1988: 9.6.2), la tessera de Bílbilis (Balil, 1987: 332; BD Hispania Epigraphica, n.o 24964), y dudamos sobre la pieza sin apelativo de Empúries (Almagro, 1952: 134; Balil, 1987; Mayer y Rodà, 1988, 9.1.5; IRC V, 164) aunque la mantenemos en el registro. A causa de no conocer exactamente su procedencia, no se han incorporado al conjunto algunas decenas de fichas (especialmente de colecciones de museos). Algunas de estas exclusiones merecen un razonamiento específico; mantenemos fuera de la lista la pieza de Tarragona de la Colección Hernández Sanahuja debido a su procedencia italiana (CIL II, 4936,2), o la pieza del museo de Chieti (Baratta, 2015: n. 10), que, aparte de su incierta procedencia, cabe sumar su inédita inscripción y el particular tratamiento del campo epigráfico. También queremos reseñar la propuesta alternativa sobre las tesserae con numeral $X X X$ e inscripción $V E L$, puesto que podría tratarse de fichas que aluden a la tribu Velina asociada al número del orden de éstas (Crawford, 2002: 1128 y 1135).

5 Nos referimos esencialmente al lote de piezas procedentes de Roma (Huelsen, 1896: n. ${ }^{\text {os }} 46-68$ ). 


\begin{tabular}{|c|c|c|c|c|c|c|c|c|}
\hline \multicolumn{9}{|c|}{ HISPANIA CITERIOR } \\
\hline ID & \multicolumn{2}{|l|}{$\begin{array}{l}\text { LUGAR DE } \\
\text { HALLAZGO }\end{array}$} & N. ${ }^{\circ}$ & REF. BIBLIOGRAF. & $\begin{array}{l}\text { RDGUEZ. } \\
\text { MARTÍN, } \\
2016 \\
\end{array}$ & APELATIVO & NUMERAL & $\begin{array}{c}\text { CONTEXTO } \\
\text { Y DATACIÓN } \\
\text { ARQUEOLÓGICA }\end{array}$ \\
\hline 1 & \multirow{7}{*}{\multicolumn{2}{|c|}{ Empúries }} & 1 & $\begin{array}{l}\text { Almagro, 1952: 133; Balil, 1987; Mayer y } \\
\text { Rodà, 1988: 9.1.1; IRC, v: } 160\end{array}$ & $\mathrm{x}$ & NVGO & I & --- \\
\hline 2 & & & 2 & $\begin{array}{l}\text { Almagro, 1952: 132; Balil, 1987; Mayer y } \\
\text { Rodà, 1988, 9.1.2; IRC, v: } 161\end{array}$ & $\mathrm{x}$ & $T V B E$ & $x$ & -- \\
\hline 3 & & & 3 & $\begin{array}{l}\text { Almagro, 1952: 135; Balil, 1987; Mayer y } \\
\text { Rodà, 1988: 9.1.3; IRC, v: } 162\end{array}$ & $\mathrm{x}$ & AVDAX & $X X I$ & -- \\
\hline 4 & & & 4 & $\begin{array}{l}\text { Almagro, 1952: 130; Balil, 1987; Mayer y } \\
\text { Rodà, 1988: 9.1.4; IRC, v: } 163\end{array}$ & $\mathrm{x}$ & FORTVNATE & XXIIII & Muralla Robert \\
\hline 5 & & & 5 & $\begin{array}{l}\text { Almagro, 1952: 134; Balil, 1987; Mayer y } \\
\text { Rodà, 1988: 9.1.5; IRC, v: } 164\end{array}$ & $\mathrm{x}$ & no inscrita & XXIII & --- \\
\hline 6 & & & 6 & $\begin{array}{l}\text { Almagro, 1952: 136; Balil, 1987; Mayer y } \\
\text { Rodà, 1988: 9.1.6; IRC, v: } 165\end{array}$ & $\mathrm{x}$ & CL[---] & XX[---] & -- \\
\hline 7 & & & 7 & $\begin{array}{l}\text { Almagro, 1952: 134; Balil, 1987; Mayer y } \\
\text { Rodà, 1988: 9.1.7; IRC, v: } 166\end{array}$ & $\mathrm{x}$ & AMATOR & {$[--]$} & --- \\
\hline 8 & \multicolumn{2}{|c|}{ Puig Castell - Lauro } & 1 & inédita & 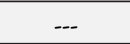 & GVLO & IIII & hábitat; $75-50 \mathrm{aC}$ \\
\hline 9 & \multicolumn{2}{|l|}{ Tortosa } & 1 & $\begin{array}{l}\text { Mayer y Rodà, 1988: 9.4; IRC, v: } 170 \text {; } \\
\text { Rodríguez Martín, 2016: n. } 13 .\end{array}$ & $\mathrm{x}$ & FORTVNAT(VS) & {$[X] X I I I I$} & \\
\hline 10 & \multicolumn{2}{|l|}{ Saguntum } & 1 & Corell, 2002: n. 311 & $\mathrm{x}$ & FORTVNATE & XXIIII & sin contexto \\
\hline 11 & \multicolumn{2}{|l|}{ Elche } & 1 & Abascal, 2012; AE 2012, 807. & $\mathrm{x}$ & PERNIX & XVII & urbano; ante 50 a. C. \\
\hline 12 & \multicolumn{2}{|l|}{ Talamanca-Ibiza } & 1 & Veny, 1965: n. 194; Baratta, 2014: n. 1 & $\mathrm{x}$ & PERNIX & XVII & funerario \\
\hline 13 & \multicolumn{2}{|l|}{ La Alcudia } & 1 & Veny, 1965: n. 60; Baratta, 2014: n. 2 & $\mathrm{x}$ & PERNIX & XVII & sin contexto \\
\hline \multicolumn{9}{|c|}{ GALLIA NARBONENSIS } \\
\hline 14 & \multicolumn{2}{|l|}{ Ruscino } & 1 & Baratta, 2015 & & \begin{tabular}{|l|} 
QVAISTOR \\
apelativo inédito
\end{tabular} & XII & superficial \\
\hline 15 & \multicolumn{2}{|l|}{ Avignon } & 1 & Carru y Tallah, 2015: 137, fig. 104 & & GVMIA & $?$ & $-\ldots$ \\
\hline \multicolumn{9}{|c|}{ ITALIA } \\
\hline 16 & \multirow{17}{*}{\multicolumn{2}{|c|}{ 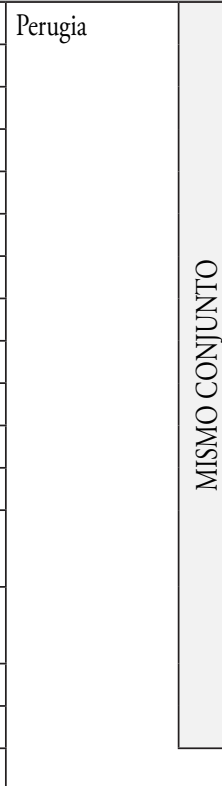 }} & 1 & Huelsen, 1896: n. ${ }^{\circ}$ 1; $A E, 1888: 116 \mathrm{c}$ & $\mathrm{x}$ & MOICE & III & funerario; s. II a. C. \\
\hline 17 & & & 2 & Huelsen, 1896: n..$^{\circ}$; $A E, 1888: 116 \mathrm{~d}$ & $\mathrm{x}$ & PATICE & VIII & funerario; s. II a. C. \\
\hline 18 & & & 3 & Huelsen, 1896: n. ${ }^{\circ}$ 3; $A E, 1888: 116 \mathrm{e}$ & $\mathrm{x}$ & {$[V A] P P A$} & VIII & funerario; s. II a. C. \\
\hline 19 & & & 4 & Huelsen, 1896: n. ${ }^{\circ} 4 ; A E, 1888: 116 f$ & $\mathrm{x}$ & VIX'RIDES & XIII & funerario; s. II a. C. \\
\hline 20 & & & 5 & Huelsen, 1896: n. ${ }^{\circ}$ 5; $A E, 1888: 116 \mathrm{~g}$ & $\mathrm{x}$ & MORARIS & XIIII & funerario; s. II a. C. \\
\hline 21 & & & 6 & Huelsen, 1896: n. ${ }^{\circ}$ 6; $A E, 1888: 116 \mathrm{~h}$ & $\mathrm{x}$ & ARGVTE & $X V$ & funerario; s. II a. C. \\
\hline 22 & & & 7 & Huelsen, 1896: n.o 7; $A E$, 1888: 116i & $\mathrm{x}$ & PERNIX & XVII & funerario; s. II a. C. \\
\hline 23 & & & 8 & Huelsen, 1896: n. ${ }^{\circ} 8$ & $\mathrm{x}$ & --- & XVIII & funerario; s. II a. C. \\
\hline 24 & & & 9 & Huelsen, 1896: n. ${ }^{\circ}$ 9; $A E, 1888: 116 \mathrm{k}$ & $\mathrm{x}$ & BENIGNVS & $X X A L$ & funerario; s. II a. C. \\
\hline 25 & & & 10 & Huelsen, 1896: n. ${ }^{\circ} 10$ & $\mathrm{x}$ & AMATOR & $X X X$ & funerario; s. II a. C. \\
\hline 26 & & & 11 & Huelsen, 1896: n. ${ }^{\circ} 11 ; A E, 1888: 1161$ & $\mathrm{x}$ & FELIX & $I X$ & funerario; s. II a. C. \\
\hline 27 & & & 12 & Huelsen, 1896: n. ${ }^{\circ} 12$ & $\mathrm{x}$ & FVCCO & $--A$ & funerario; s. II a. C. \\
\hline 28 & & & 13 & $\begin{array}{l}\text { Huelsen, 1896: n. }{ }^{\circ} \text { 13; Casagrande, 2012: } \\
250\end{array}$ & $\mathrm{x}$ & PIGER & V & funerario; s. II a. C. \\
\hline 29 & & & 14 & $\begin{array}{l}\text { Huelsen, 1896: n. }{ }^{\circ} \text { 14; Casagrande, } 2012 \text { : } \\
250\end{array}$ & $\mathrm{x}$ & [F]ACETE & -- & funerario; s. II a. C. \\
\hline 30 & & & 15 & Huelsen, 1896: n. ${ }^{\circ} 15$ & $\mathrm{x}$ & TVBE & $-\ldots$ & funerario; s. II a. C. \\
\hline 31 & & & 16 & Huelsen, 1896: s/n & $\mathrm{x}$ & no inscrita & no inscrita & funerario; s. II a. C. \\
\hline 32 & & & 17 & Huelsen, 1896: n. ${ }^{\circ} 17$ & $\mathrm{x}$ & FATVE & $X I$ & --- \\
\hline
\end{tabular}


182 Marc Guàrdia i Llorens / La tessera lusoria del Puig del Castell de Samalús (Barcelona): ¿más que fichas de juego?

\begin{tabular}{|c|c|c|c|c|c|c|c|c|}
\hline ID & \multicolumn{2}{|c|}{$\begin{array}{l}\text { LUGAR DE } \\
\text { HALLAZGO }\end{array}$} & N.o & REF. BIBLIOGRAF. & $\begin{array}{l}\text { RDGUEZ. } \\
\text { MARTÍN, } \\
2016 \\
\end{array}$ & APELATIVO & NUMERAL & $\begin{array}{c}\text { CONTEXTO } \\
\text { Y DATACIÓN } \\
\text { ARQUEOLÓGICA }\end{array}$ \\
\hline 33 & \multirow[t]{17}{*}{ Vaste } & \multirow{17}{*}{ 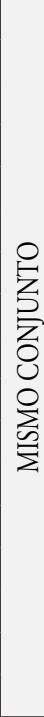 } & 1 & Campagna, 1995: n. ${ }^{\circ} 1$ & $\mathrm{x}$ & $N V G O$ & $I$ & cisterna; $150-125$ a. C. \\
\hline 34 & & & 2 & Campagna, 1995: n. ${ }^{\circ} 2$ & $\mathrm{x}$ & EBRIOSE & $I V$ & cisterna; $150-125$ a. C. \\
\hline 35 & & & 3 & Campagna, 1995: n. ${ }^{\circ} 3$ & $\mathrm{x}$ & PERIVRE & IIII A & cisterna; $150-125$ a. C. \\
\hline 36 & & & 4 & Campagna, 1995: n. ${ }^{\circ} 4$ & $\mathrm{x}$ & FICOSE & V & cisterna; $150-125$ a. C. \\
\hline 37 & & & 5 & Campagna, 1995: n. ${ }^{\circ} 5$ & $\mathrm{x}$ & PATICE & VIII & cisterna; $150-125$ a. C. \\
\hline 38 & & & 6 & Campagna, 1995: n. ${ }^{\circ} 6$ & $\mathrm{x}$ & SCVLTVMO & VIIII & cisterna; $150-125$ a. C. \\
\hline 39 & & & 7 & Campagna, 1995: n. ${ }^{\circ} 7$ & $\mathrm{x}$ & TVBE & $x$ & cisterna; $150-125$ a. C. \\
\hline 40 & & & 8 & Campagna, 1995: n.o 8 & $\mathrm{x}$ & TRICO & $X I A$ & cisterna; $150-125$ a. C. \\
\hline 42 & & & 9 & Campagna, 1995: n. ${ }^{\circ} 9$ & $\mathrm{x}$ & $F V R$ & XIII & cisterna; $150-125$ a. C. \\
\hline 43 & & & 10 & Campagna, 1995: n.o 10 & $\mathrm{x}$ & AMATOR & XIIII & cisterna; $150-125$ a. C. \\
\hline 44 & & & 11 & Campagna, 1995: n.o 11 & $\mathrm{x}$ & AVIDVS & $X V$ & cisterna; $150-125$ a. C. \\
\hline 45 & & & 12 & Campagna, 1995: n. ${ }^{\circ} 12$ & $\mathrm{x}$ & BONVS & $X V I I$ & cisterna; $150-125$ a. C. \\
\hline 46 & & & 13 & Campagna, 1995: n.o 13 & $\mathrm{x}$ & PVRVS & XIIX & cisterna; $150-125$ a. C. \\
\hline 47 & & & 14 & Campagna, 1995: n.o 14 & $\mathrm{x}$ & SERIVS & $X I X$ & cisterna; $150-125$ a. C. \\
\hline 48 & & & 15 & Campagna, 1995: n. ${ }^{\circ} 15$ & $\mathrm{x}$ & BENEST & $X X V$ & cisterna; $150-125$ a. C. \\
\hline 49 & & & 16 & Campagna, 1995: n. ${ }^{\circ} 16$ & $\mathrm{x}$ & FELLIX & $X X X$ & cisterna; $150-125$ a. C. \\
\hline 50 & & & 17 & Campagna, 1995: n. ${ }^{\circ} 17$ & $\mathrm{x}$ & REX & $L X$ & cisterna; $150-125$ a. C. \\
\hline 51 & \multirow[t]{19}{*}{ Siracusa } & \multirow{19}{*}{ 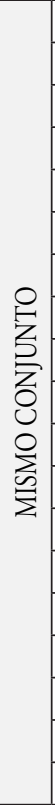 } & 1 & Orsi, 1920: 320, n. ${ }^{\circ} 1$ y fig. 12 & & $E G O$ & $X X V$ & fosa en anfiteatro \\
\hline 52 & & & 2 & Orsi, 1920: 320, n. $^{\circ} 2$ & & VALEO = VAPIO? & $I V$ & fosa en anfiteatro \\
\hline 53 & & & 3 & Orsi, 1920: 320, n. $^{\circ} 3$ & & $E G O$ & $X I$ & fosa en anfiteatro \\
\hline 54 & & & 4 & Orsi, 1920: 320, n. $^{\circ} 4$ & & CI/IIAIA & --- & fosa en anfiteatro \\
\hline 55 & & & 5 & Orsi, 1920: 320, n. ${ }^{\circ} 5$ & & $E G O=N V G O ?$ & $I$ & fosa en anfiteatro \\
\hline 56 & & & 6 & Orsi, 1920: 320, n. ${ }^{\circ} 6$ & & $\ldots G V S=$ CINAIDVS? & VII & fosa en anfiteatro \\
\hline 57 & & & 7 & Orsi, 1920: 320, n. $^{\circ} 7$ & & --- & $X I I$ & fosa en anfiteatro \\
\hline 58 & & & 8 & Orsi, 1920: 320, n. ${ }^{\circ} 8$ & & --- & V & fosa en anfiteatro \\
\hline 59 & & & 9 & Orsi, 1920: 320, n. $^{\circ} 9$ & & --- & $V I$ & fosa en anfiteatro \\
\hline 60 & & & 10 & Orsi, 1920: 320, n. $^{\circ} 10$ & & --- & $x$ & fosa en anfiteatro \\
\hline 61 & & & 11 & Orsi, 1920 & & ilegible & ilegible & fosa en anfiteatro \\
\hline 62 & & & 12 & Orsi, 1920 & & ilegible & ilegible & fosa en anfiteatro \\
\hline 63 & & & 13 & Orsi, 1920 & & ilegible & ilegible & fosa en anfiteatro \\
\hline 64 & & & 14 & Orsi, 1920 & & ilegible & ilegible & fosa en anfiteatro \\
\hline 65 & & & 15 & Orsi, 1920 & & ilegible & ilegible & fosa en anfiteatro \\
\hline 66 & & & 16 & Orsi, 1920 & & ilegible & ilegible & fosa en anfiteatro \\
\hline 67 & & & 17 & Orsi, 1920 & & ilegible & ilegible & fosa en anfiteatro \\
\hline 68 & & & 18 & Orsi, 1920 & & ilegible & ilegible & fosa en anfiteatro \\
\hline 69 & & & 19 & no contabilizada en Orsi, 1920 & & ilegible & ilegible & fosa en anfiteatro \\
\hline 70 & \multirow{11}{*}{\multicolumn{2}{|c|}{ Pompeya }} & 1 & Huelsen, 1896: n. ${ }^{\circ} 18$ & $\mathrm{x}$ & EBRIOSE & IIII & --- \\
\hline 71 & & & 2 & Huelsen, 1896: n. ${ }^{\circ}$ 19; Gusman, 1900:169? & $\mathrm{x}$ & VAPIO & IIII & --- \\
\hline 72 & & & 3 & Huelsen, 1896: n. ${ }^{\circ} 20$ & $\mathrm{x}$ & CVNV.LINGE & $V I$ & --- \\
\hline 73 & & & 4 & Huelsen, 1896: n. ${ }^{\circ} 21$ & $\mathrm{x}$ & BENIGNE & $X X X A$ & --- \\
\hline 74 & & & 5 & Huelsen, 1896: n. ${ }^{\circ} 22$ & $\mathrm{x}$ & ARPAX & $X I X$ & --- \\
\hline 75 & & & 6 & Franchi dell'Orto, 1994: n. ${ }^{\circ} 86$ & & HARPAX & V & Vicolo del Gallo \\
\hline 76 & & & 7 & Franchi dell'Orto, 1994: n. ${ }^{\circ} 87$ & & FACETE & $X X V$ & $\mathrm{I}, 18,3$ \\
\hline 77 & & & 8 & Finati, 1843: 119 & & PERNIX & III O XX O XVIII O XXVI & Casa del Cirujano \\
\hline 78 & & & 9 & Finati, 1843: 119; Gusman, 1900: 169? & & VAPIO & III O XX O XVIII O XXVI & Casa del Cirujano \\
\hline 79 & & & 10 & Finati, 1843: 119 & & ARPAX & III O XX O XVIII O XXVI & Casa del Cirujano \\
\hline 80 & & & 11 & Gusman, 1900: 169 & & $?$ & $X I V$ & \\
\hline
\end{tabular}




\begin{tabular}{|c|c|c|c|c|c|c|c|}
\hline ID & $\begin{array}{l}\text { LUGAR DE } \\
\text { HALLAZGO }\end{array}$ & N.o & REF. BIBLIOGRAF. & $\begin{array}{l}\text { RDGUEZ. } \\
\text { MARTÍN, } \\
2016\end{array}$ & APELATIVO & NUMERAL & $\begin{array}{c}\text { CONTEXTO } \\
\text { Y DATACIÓN } \\
\text { ARQUEOLÓGICA }\end{array}$ \\
\hline 81 & Cremona & 1 & Cecchini et al., 2015 & $\mathrm{x}$ & FICOSE & $X I V$ & $\begin{array}{l}\text { Cripta de } \\
\text { Sant'Omobono; } \\
\text { augústeo-tiberiano }\end{array}$ \\
\hline 82 & Monte Iato & 1 & ILER, 2003: 835, t. CXXXIV, 2-3 & & TRICO & $X I A$ & $\begin{array}{l}\text { urbano; } \\
\text { tiberiano-claudio }\end{array}$ \\
\hline 83 & \multirow[t]{2}{*}{ Cumas } & 1 & Huelsen, 1896: n. ${ }^{\circ} 30$ & $\mathrm{x}$ & CINAIDVUS & VII & $-\ldots$ \\
\hline 84 & & 2 & Huelsen, 1896: n. ${ }^{\circ} 31$ & $\mathrm{x}$ & PERNIX & $X V I I$ & -- \\
\hline 85 & Paestum & 1 & Huelsen, 1896: n. ${ }^{\circ} 42$ & $\mathrm{x}$ & FACETE & $X X V$ & $-\ldots$ \\
\hline 86 & Populonia & 1 & De Palma et al., 2011: fig. 6 & & PATICE & VIII & urbano/templo; s. I a. C. \\
\hline 87 & Frosinone & 1 & Huelsen, 1896: n. ${ }^{\circ} 35$ & $\mathrm{x}$ & CVNV.LINGE & VIII & anfiteatro \\
\hline 88 & \multirow[t]{6}{*}{ Pentima, Corfinio } & 1 & NSA 1879: 185a; Huelsen, 1896: n.o 36 & $\mathrm{x}$ & $F V R$ & II A & $-\ldots$ \\
\hline 89 & & 2 & NSA, 1879: 185b; Huelsen, 1896: n. ${ }^{0} 37$ & $\mathrm{x}$ & VAPIO & VIII A & $\ldots$ \\
\hline 90 & & 3 & $\begin{array}{l}\text { NSA 1879: 317a; Huelsen, 1896: n. }{ }^{\circ} 38 ; \\
\text { Baratta, 2015: n. } 15\end{array}$ & $\mathrm{x}$ & CVNNIO & XVIII $($ Huelsen $=X)$ & -.- \\
\hline 91 & & 4 & NSA, 1879: 185c; Huelsen, 1896: n. ${ }^{\circ} 39$ & $\mathrm{x}$ & FVVCO & XII A & --- \\
\hline 92 & & 5 & $\begin{array}{l}\text { NSA, 1879: 317b; Huelsen, 1896: n. }{ }^{\circ} \text { 40; } \\
\text { Baratta, 2015: n. } 15\end{array}$ & $\mathrm{x}$ & ARPAX & $\begin{array}{l}X I I \\
\text { (Huelsen = XVIII) }\end{array}$ & --- \\
\hline 93 & & 6 & NSA, 1886: 422; Huelsen, 1896: n. ${ }^{\circ} 41$ & $\mathrm{x}$ & GVMIA & XXI & $\ldots$ \\
\hline 94 & \multirow[t]{2}{*}{ Viterbo - Ferentum } & 1 & Zei, 1921: fig. 4 & $\mathrm{x}$ & VAPIO & IVA & funerario; s. II a. C. \\
\hline 95 & & 2 & Zei, 1921: fig. 5 & $\mathrm{x}$ & FATVE & $X X A$ & funerario; s. II a. C. \\
\hline 96 & \multirow[t]{2}{*}{ Morgantina } & 1 & Campagna, 1995: 283, n. 71 & & ARGVTE & $?$ & urbano \\
\hline 97 & & 2 & Campagna, 1995: 283, n. 71 & & $?$ & $?$ & urbano \\
\hline 98 & Chiusi & 1 & Banducci, 2015: 201; Huelsen, 1896: n. ${ }^{\circ} 16$ & CG & GVLO & IIII & --- \\
\hline 99 & Cales & 1 & Huelsen, 1896: n. ${ }^{\circ} 27 ;$ CIL x 8070,16 & $\mathrm{x}$ & VAPIO & IV AL & $\ldots$ \\
\hline 100 & \multirow[t]{6}{*}{ Nápoles } & 1 & Huelsen, 1896: n. ${ }^{\circ} 28$ & $\mathrm{x}$ & VIX RIDES & XIII & --. \\
\hline 101 & & 2 & Huelsen, 1896: n. ${ }^{\circ} 29$ & $\mathrm{x}$ & VEL & $X X X$ & $-\ldots$ \\
\hline 102 & & 3 & Huelsen, 1896: n. ${ }^{\circ} 32$ & $\mathrm{x}$ & NVGATOR & $I$ & -- \\
\hline 103 & & 4 & Huelsen, 1896: n. ${ }^{\circ} 33$ & $\mathrm{x}$ & $F V R$ & II & $-\ldots$ \\
\hline 104 & & 5 & Huelsen, 1896: n. ${ }^{\circ} 34$ & $\mathrm{x}$ & PERNIX & $X V I I$ & --- \\
\hline 105 & & 6 & Huelsen, 1896: n. ${ }^{\circ} 82$ & BM & STVMACOSE & II A & --- \\
\hline 106 & Atri & 1 & Huelsen, 1896: n. ${ }^{\circ} 44$ & $\mathrm{x}$ & PATICEN & VIII & --- \\
\hline 107 & \multirow[t]{17}{*}{ Roma (cf.n. 5) } & 1 & Huelsen, 1896: n. ${ }^{\circ} 46$ & $\mathrm{x}$ & MOICE & III A & $-\ldots$ \\
\hline 108 & & 2 & Huelsen, 1896: n. ${ }^{\circ} 47$ & $\mathrm{x}$ & $M V L A$ & $V I$ & --- \\
\hline 109 & & 3 & Huelsen, 1896: n. ${ }^{\circ} 48$ & $\mathrm{x}$ & ARPAX & XVIIII & 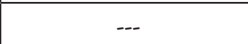 \\
\hline 110 & & 4 & Huelsen, 1896: n. ${ }^{\circ} 49$ & $\mathrm{x}$ & GAVDESNE & $X I$ & -.- \\
\hline 111 & & 5 & Huelsen, 1896: n. ${ }^{\circ} 50$ & $\mathrm{x}$ & VERECVND & XII & $-\ldots$ \\
\hline 112 & & 6 & Huelsen, 1896: n. ${ }^{\circ} 51$ & $\mathrm{x}$ & ARPAX & XVIIII & --- \\
\hline 113 & & 7 & Huelsen, 1896: n. ${ }^{\circ} 52$ & $\mathrm{x}$ & INPVDES & XXII & --- \\
\hline 114 & & 8 & Huelsen, 1896: n. ${ }^{\circ} 53$ & $\mathrm{x}$ & FICOSE & VII & $-\ldots$ \\
\hline 115 & & 9 & Huelsen, 1896: n. ${ }^{0} 54$ & $\mathrm{x}$ & FATVE & $X V I I$ & $\ldots$ \\
\hline 116 & & 10 & Huelsen, 1896: n. ${ }^{0} 55$ & $\mathrm{x}$ & FACETE & XI PAL & 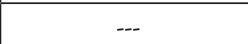 \\
\hline 117 & & 11 & Huelsen, 1896: n. ${ }^{\circ} 56$ & $\mathrm{x}$ & VAPIO & VIII A & -.- \\
\hline 118 & & 12 & Huelsen, 1896: n. ${ }^{0} 57$ & $\mathrm{x}$ & TRICO & $X I$ & $-\ldots$ \\
\hline 119 & & 13 & Le Blant, 1888: 104; Huelsen, 1896: n. ${ }^{\circ} 58$ & $\mathrm{x}$ & EBRIOSE & IIII & -- \\
\hline 120 & & 14 & Le Blant, 1888: 104; Huelsen, 1896: n. ${ }^{\circ} 59$ & $\mathrm{x}$ & AMATOR & $X X X$ & --- \\
\hline 121 & & 15 & Huelsen, 1896: n. ${ }^{\circ} 60$ & $\mathrm{x}$ & VAPIO & VIII A & --- \\
\hline 122 & & 16 & Huelsen, 1896: n. ${ }^{\circ} 61$ & $\mathrm{x}$ & ARGVTE & $X V$ & $-\ldots$ \\
\hline 123 & & 17 & Huelsen, 1896: n. ${ }^{\circ} 62$ & $\mathrm{x}$ & EBRIOSE & IIII & $-\ldots$ \\
\hline
\end{tabular}


184 Marc Guàrdia i Llorens / La tessera lusoria del Puig del Castell de Samalús (Barcelona): ¿más que fichas de juego?

\begin{tabular}{|c|c|c|c|c|c|c|c|}
\hline ID & $\begin{array}{l}\text { LUGAR DE } \\
\text { HALLAZGO }\end{array}$ & N.o & REF. BIBLIOGRAF. & $\begin{array}{l}\text { RDGUEZ. } \\
\text { MARTÍN, } \\
2016 \\
\end{array}$ & APELATIVO & NUMERAL & $\begin{array}{c}\text { CONTEXTO } \\
\text { Y DATACIÓN } \\
\text { ARQUEOLÓGICA }\end{array}$ \\
\hline 124 & \multirow[t]{6}{*}{ Roma (cf. n. 5) } & 18 & Huelsen, 1896: n. ${ }^{\circ} 63$ & $\mathrm{x}$ & PATICE & VII & --- \\
\hline 125 & & 19 & Huelsen, 1896: n. ${ }^{\circ} 64$ & $\mathrm{x}$ & LVPA & $X V I$ & $-\ldots$ \\
\hline 126 & & 20 & Huelsen, 1896: n. ${ }^{\circ} 65$ & $\mathrm{x}$ & FATVE & XIIII & --- \\
\hline 127 & & 21 & Huelsen, 1896: n. ${ }^{\circ} 66$ & $\mathrm{x}$ & GVMIA & $X X$ & -.- \\
\hline 128 & & 22 & Huelsen, 1896: n. ${ }^{\circ} 67$ & $\mathrm{x}$ & FORTVNAT & XXIIII & --- \\
\hline 129 & & 23 & Huelsen, 1896: n. ${ }^{\circ} 68$ & $\mathrm{x}$ & PERNIX & XVII & --- \\
\hline 130 & \multirow[t]{4}{*}{ Corneto } & 1 & $\begin{array}{l}\text { Huelsen, 1896: n. }{ }^{\circ} \text { 69; Colivicchi, 2007: } \\
\text { n. 507; Baratta, 2015 }\end{array}$ & $\mathrm{x}$ & LVPA & $X I I \quad($ Baratta=IIX $)$ & --- \\
\hline 131 & & 2 & $\begin{array}{l}\text { Huelsen, 1896: n. }{ }^{\circ} \text { 69a; Colivicchi, 2007: } \\
\text { n. } 506\end{array}$ & $\mathrm{x}$ & NVGATOR & $X I$ & --- \\
\hline 132 & & 3 & Helbig, 1877: 118; Colivicchi, 2007: 206 & & MOICE & III & funerario \\
\hline 133 & & 4 & Helbig, 1877: 118; Colivicchi, 2007: 206 & & {$[F] \operatorname{AATV}[E]$} & $V[---]$ & funerario \\
\hline 134 & \multirow[t]{2}{*}{ Vetulonia } & 1 & CIL XI 6728,25 & & PERIVRE & IIII & --- \\
\hline 135 & & 2 & CIL XI 6728, 21 & & CINAEDE & VIII & --- \\
\hline 136 & Cortona & 1 & CIL XI 6728, 20 & & AMATOR & $X I$ & --- \\
\hline 137 & Florencia & 1 & Huelsen, 1896: n. ${ }^{\circ} 69$ & $\mathrm{x}$ & FORTVNATE & XXIIII & --- \\
\hline 138 & Gabii & 1 & Banducci, 2015 & & GVLO & IIII & funerario; s. I d. C. \\
\hline 139 & Larinum & 1 & De Felice, 1994: 58; Stelluti, 1997: 266 & & PATICE & VIII & --- \\
\hline \multicolumn{8}{|c|}{ GRECIA } \\
\hline 140 & \multirow[t]{8}{*}{ Delos } & 1 & Deonna, 1938: 335, в5421 & $\mathrm{x}$ & FELIX & XII & urbano; ante 88 a. C. \\
\hline 141 & & 2 & Deonna, 1938: 335, в5422-6591 & $\mathrm{x}$ & VIX RIDES & XIII & $\begin{array}{l}\text { o de la stoa; } \\
\text { ante } 88 \text { a. C. }\end{array}$ \\
\hline 142 & & 3 & Deonna, 1938: 335, в1111-7802 & $\mathrm{x}$ & ARPAX & XIIII & $\begin{array}{l}\text { templo de Artemis; ante } \\
88 \text { a. C. }\end{array}$ \\
\hline 143 & & 4 & Deonna, 1938: 335, в5423-6717 & $\mathrm{x}$ & AVIDVS & XVIII & $\begin{array}{l}\text { ágora romana; } \\
\text { ante } 88 \text { a. C. }\end{array}$ \\
\hline 144 & & 5 & Deonna, 1938: 335, в1112-7803 & $\mathrm{x}$ & VINOSE & XVIIII & $\begin{array}{l}\text { templo de Artemis; ante } \\
88 \text { a. C. }\end{array}$ \\
\hline 145 & & 6 & Deonna, 1938: 335, в5424 & $\mathrm{x}$ & $P V L$ & $X X$ & $\begin{array}{l}\text { ágora romana; } \\
\text { ante } 88 \text { a. C. }\end{array}$ \\
\hline 146 & & 7 & Deonna, 1938: 335, в5425-7010 & $\mathrm{x}$ & AMATOR & $X X X$ & $\begin{array}{l}\text { insula de la Casa de } \\
\text { Dionisos; ante } 88 \text { a. C. }\end{array}$ \\
\hline 147 & & 8 & Deonna, 1938: 335, в5420 & $\mathrm{x}$ & no inscrita & no inscrita & $\begin{array}{l}\text { insula de la Casa de } \\
\text { Dionisos; ante } 88 \text { a. C. }\end{array}$ \\
\hline
\end{tabular}

FIG. 5. Recopilación de tesserae lusoriae con procedencia conocida.

restringido el carácter de su inclusión, puede haber algún error en la información publicada, aunque creemos que, en ningún caso, sería significativo, a tenor del volumen total de hallazgos.

El resultado ha sido un conjunto de 146 tesserae lusoriae, exclusivamente de procedencia conocida. Respecto de la última compilación, en la que se recogían tanto fichas de hallazgo concreto como desconocido (Rodríguez Martín, 2016), hemos aumentado la muestra en 38 nuevas fichas sobre las de lugar conocido, que representa un $26 \%$ sobre el total.

Para comprender el alcance de la presencia de este tipo de fichas de juego en la Citerior es igualmente importante trazar su posible lugar de producción, así como su área de difusión. Del análisis de los hallazgos podemos extraer algunas conclusiones interesantes (Fig. 6). En primer lugar, queda claro que el fenómeno de las tesserae lusoriae es bastante transversal en lo que se refiere a su localización italiana, 


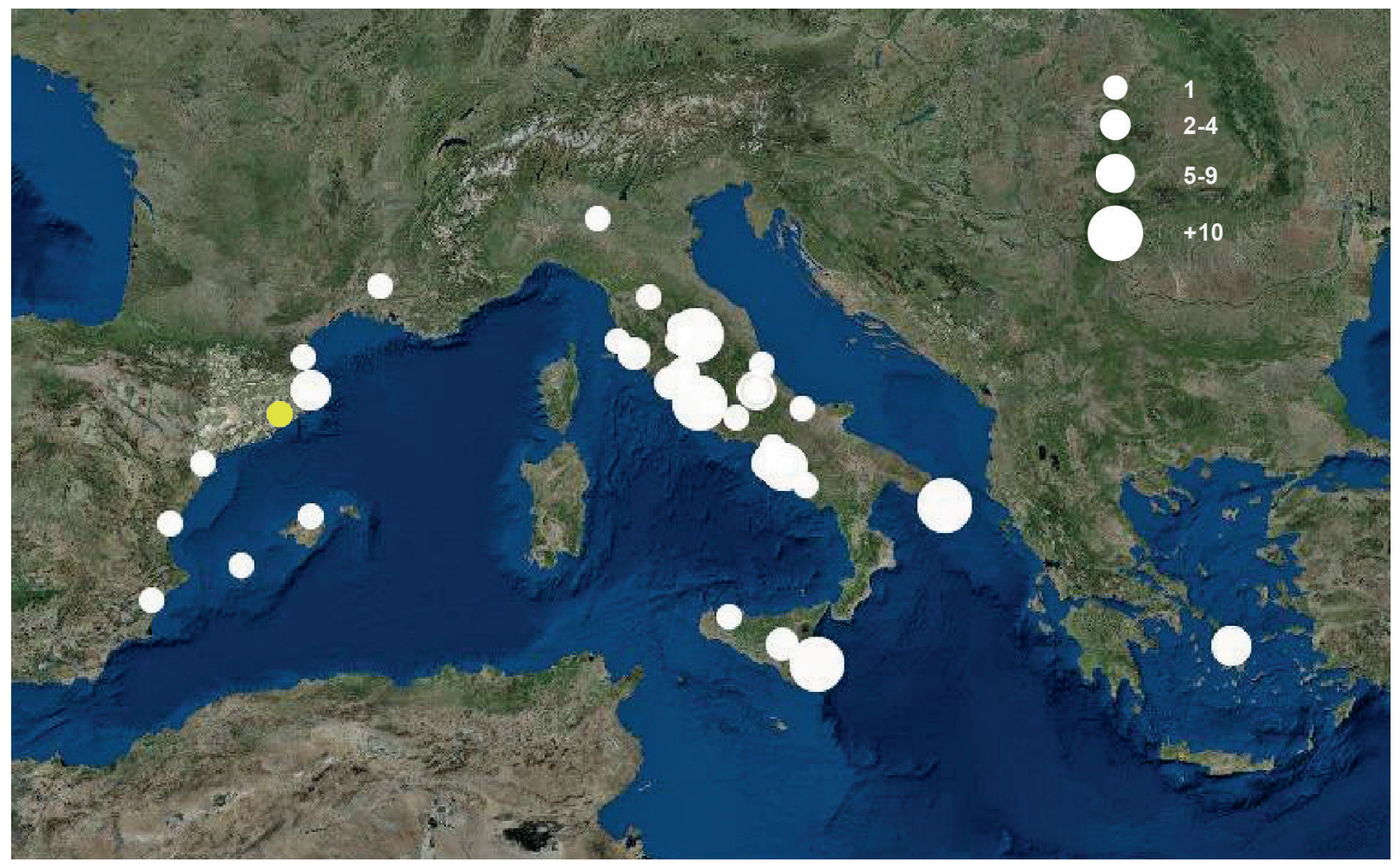

FIG. 6. Distribución de los hallazgos de tesserae lusoriae.

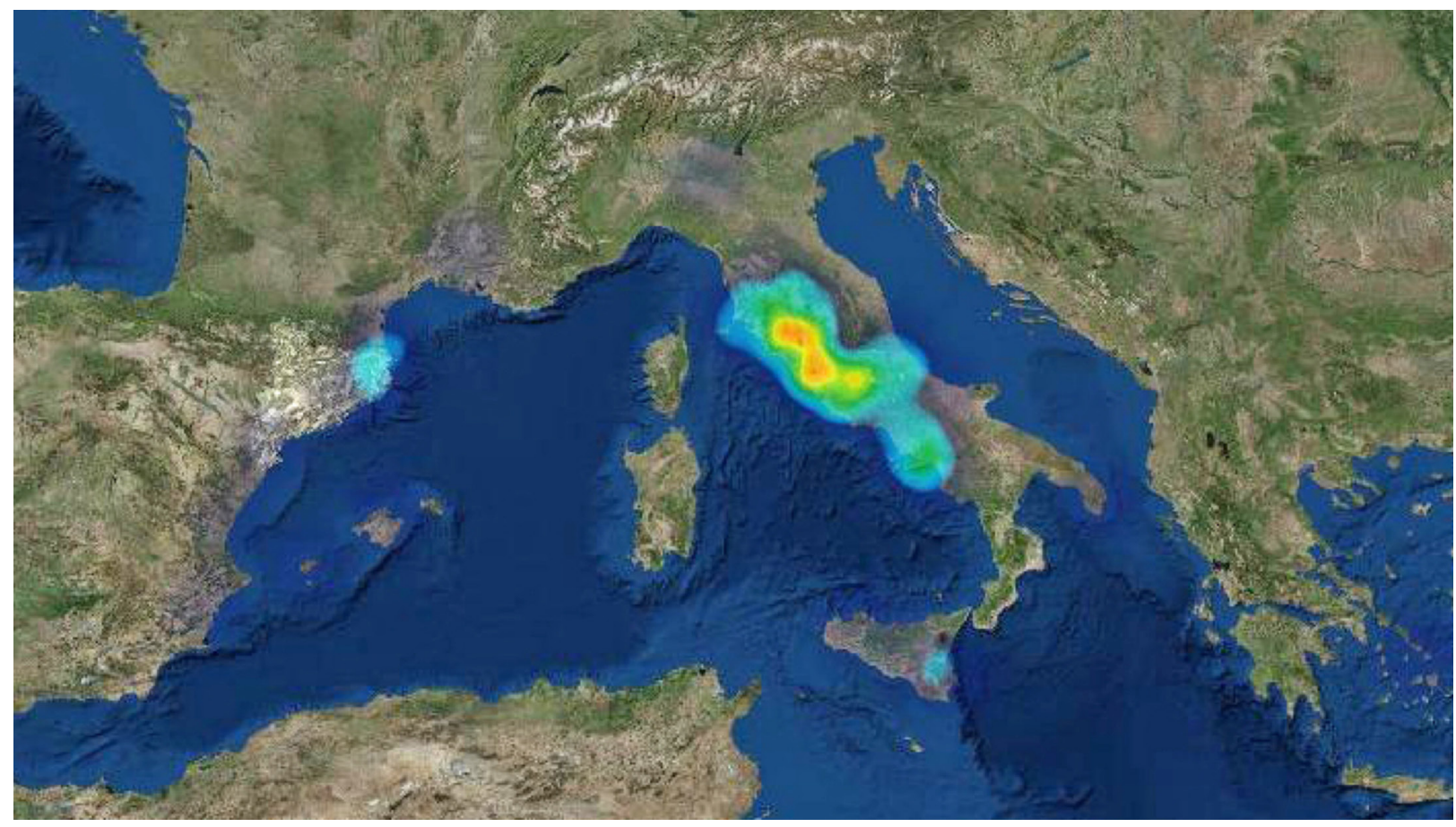

Fig. 7. Gráfico de concentración de los hallazgos. 
lugar inequívoco de su producción, encontrándose 124 piezas en 24 ubicaciones distintas. Esencialmente se distribuyen en la zona central de la península, Etruria, Lacio y Campania, con presencia significativa en Sicilia. Si nos fijamos en el mapa de calor sobre su distribución (Fig. 7) el área está bien definida. Para no distorsionar la representación con los hallazgos de múltiples tesserae en los casos de Perugia, Vaste y Siracusa, al dar un valor de 1 a cada lugar de hallazgo, la concentración se cierra sobre esta área central de la península itálica. Sobresalen los casos atribuidos a Roma $-\mathrm{n}=23-\mathrm{o}$ los de Pompeya $-\mathrm{n}=11-$, aunque es más significativa la uniforme localización de tesserae en más de una quincena de yacimientos de esta zona.

Las variantes que se detectan en la correlación de atributos y numerales (Rodríguez Martín, 2016: tabla 6) pueden indicarnos que la producción no debía ser necesariamente centralizada, sino que esta diversidad se deba a focos distintos, pudiendo adaptarse a los gustos de cada zona. Esta idea vendría apoyada en los distintos acabados de las piezas que, pese a la homogeneidad tipológica de las fichas, revela tratamientos particulares -dimensiones, incisiones, apéndices-.

Fuera de territorio italiano, los hallazgos de tesserae presentan unos índices nada menospreciables; el conjunto de fichas recuperadas en la Citerior-13-, Narbonensis -2- y el caso de Delos -8- representan el 15,6\% sobre el total. Su presencia en estas tierras delata el elevado grado de romanización en época republicana.

Desde la óptica del contexto en el que se encuentran, sorprende que un apreciable 15\%, esto es, 22 fichas, lo hagan en ambientes funerarios. La cifra puede estar ligeramente desviada por el lote de Perugia, aunque hay dos lotes más en contextos no funerarios -Vaste y Siracusa-. La presencia de distintas fichas o elementos de juego en el interior de tumbas no es extraña y ha sido documentada en diversas ocasiones y territorios (Banducci, 2015: 211-212), en especial la de los astrágalos. Más allá de evidenciar su presencia, intentar abordar su explicación es más complejo. En el caso del lote de Perugia se ha expuesto que pertenecería a la persona inhumada, que ha sido catalogada de mago, atendiendo a la gran cantidad y diversidad de fichas documentadas en el hipogeo y a la interpretación del conjunto de las tesserae lusoriae como un lote de adivinación (Casagrande, 2012). En los otros sepulcros, en los que aparecen en un número mucho menor, no dejan de ser interpretados igual que el resto de los vasos de acompañamiento. Tampoco podemos descartar, especialmente para los casos funerarios no contemporáneos del fenómeno de las tesserae, que fueran utilizados como colgantes -como sería el caso del GULO de Gabii-.

Pero no olvidemos que la gran mayoría de fichas, el $85 \%$, aparecen en contextos no funerarios de diversa índole. Éstas se deben a pérdidas fortuitas en ambientes urbanos, particulares y públicos. Cabe mencionar el conjunto de Vaste, que apareció desechado de manera intencional en el interior de una cisterna. Esta intencionalidad también se trasluce en el caso siracusano, aunque solo sabemos que aparecieron tutti accumulati in una fossetta (Orsi, 1920: 319), sin llegar a comprender si se trata de un depósito o un deshecho. Desgraciadamente, la información de la que disponemos para la mayoría de los casos es poca. Es necesaria la ubicación del hallazgo y la interpretación del lugar. Aunque la pérdida del objeto sea casual, su presencia puede ser reveladora, y podemos especular sobre la relación sobre su uso con el espacio en el que se localiza la pieza. En el caso del Puig del Castell la lectura del espacio creemos que puede ayudar en la comprensión de quienes pudieron haber sido los jugadores.

\section{Significado del hallazgo}

Para comprender la tessera del Puig del Castell, primero debemos contextualizarla en el marco de los hallazgos de la Citerior. La última revisión y puesta al día ha contabilizado 12 ejemplares (Rodríguez Martín, 2016: fig. 2), a los que, una vez sumada la nuestra, completa un conjunto de 13 tesserae lusoriae, todas ellas de procedencia conocida, que provienen de 7 puntos distintos. Este dato representa solamente el $9 \%$ sobre el total de piezas de las que conocemos su origen. Si analizamos los 
yacimientos de donde proceden nos encontramos con la ciudad romana de Empúries, el municipium de Saguntum y el que se convertirá en el de Dertosa o la que acabará siendo la Colonia Iulia Ilici Augusta, más los hallazgos sin contexto claro de las Baleares. Por tanto, en época tardorrepublicana son enclaves plenamente romanizados o en vías de serlo. Este nexo común debe tener su importancia para explicar su presencia en el Puig del Castell. También vemos otras analogías con nuestro caso, al ser el nuestro un yacimiento indígena, como lo eran Arse antes de ser Saguntum, Ilici antes de ser colonia y el poco conocido enclave previo a Dertosa. Por lo tanto, podemos trazar una clara línea que nos indica el grado de romanización necesario para que tenga sentido encontrar una tessera lusoria. La observación que la presencia de este tipo de material puede ser un elemento revelador de la temprana romanización ya había sido sugerida con anterioridad, a tenor del análisis del conjunto procedente de Catalunya (Mayer y Rodà, 1988: 243).

Más allá de las particularidades del funcionamiento del juego es obvio el hecho de plantearse que la participación y entendimiento del mismo ha de llevarse a cabo por una población latinizada, que pueda comprender el sentido de más de 55 términos distintos, y que no solo debían ser comprendidos, sino que primero debían de ser leídos. Este extremo no es problemático en Empúries, pero sí que hay que explicarlo en el marco de una población ibérica. Sería un poco forzada la lectura de que se conocería estrictamente el vocabulario necesario para participar del juego. Además, la comprensión no es solo necesaria para entender las palabras, sino que se debe participar en el ambiente cultural para el que fue concebido el juego. No se trata de un juego de ocio de carácter universal, sino que está concebido para el consumo de población itálica. No se trata de un dado donde el valor numérico es compartido y entendible, y solo las combinaciones y normas pueden ser particulares, sino que se trata de un producto concebido y destinado a una comunidad concreta. Por tanto, presumimos con la posibilidad de una base romanizada para que se pueda dar el caso de encontrar una pieza de este juego.
De esta aseveración no debe deducirse automáticamente que sea imprescindible que todo el poblado del Puig del Castell está plenamente romanizado, sino que sí debía estarlo el grupo que participaba del juego.

En este sentido es factible que la pieza en cuestión no sea objeto de comercio sino parte del material de algún contingente itálico. Este extremo es particularmente interesante ya que hay un modelo similar para explicar la presencia en la costa catalana de las ánforas olearias brindisianas. El factor que explica la demanda de aceite, cuando aún no sería un producto de consumo adoptado entre las comunidades ibéricas, se ha relacionado con la presencia de grupos itálicos y especialmente consumido por la élite romana (Pera et al., 2013: 541-542; Carreras et al., 2016). Este hecho es también acorde con el registro arqueológico del Puig del Castell, puesto que en la facies republicana el Número Mínimo de Individuos -NMI- de ánforas brindisianas Giancola 5/Apani v-que son justamente un tipo en las que se envasaba aceite- es mayor que las ánforas vinarias de procedencia campano-vesuviana -aunque la muestra de ánforas importadas es aún reducida y poco representativa, no deja de ser ilustrativa, en especial sobre estos tipos poco comunes-.

Estos indicios se ven corroborados por la importante fase republicana del yacimiento, en la que se produce la reorganización de todo el sistema defensivo con la construcción de una nueva muralla, y la reocupación de las torres defensivas del ibérico pleno (Guàrdia, 2015), cuando al menos cabría esperar una reducción de la ocupación indígena, o al menos de su sistema defensivo debido a los hechos relacionables con la conquista y represión catoniana, por no mencionar los habituales abandonos y destrucciones de asentamientos en altura en este contexto histórico. Hay que añadir que al pie del cerro donde se encuentra el oppidum se construye a finales del s. II a. C. una villa republicana inequívocamente de estilo itálico, Can Martí. Concretamente correspondería a la pars urbana, de la que se han identificado el atrium, tablinum y diversas cubiculae, con decoración parietal del primer estilo pompeyano, así como mosaicos con emblema central y opus signinum 
decorados con teselas (Aquilué y Pardo, 1990). Por tanto, coincidiría en el espacio y tiempo con la fase republicana del Puig del Castell, con el que sin duda tendría una relación más que espacial y cronológica. Se abren muchos interrogantes, no sobre su filiación claramente itálica, sino sobre su función, pero el estado del conocimiento que tenemos sobre Can Martí sigue siendo parcial. Esta asociación de oppidum indígena y establecimiento romano-republicano se ha documentado en otras ocasiones, y cabe preguntarse si se debe a la presencia de gentes itálicas o a élites indígenas que ya participan del nuevo estilo de vida. Dentro de la misma Layetania este sería el caso de Burriac y el complejo de Ca l'Arnau (Cabrera de Mar), para el que se han propuesto modelos distintos. En base a las nuevas innovaciones técnicas y culturales documentadas en el nuevo complejo urbanístico se plantea una convivencia de itálicos e indígenas, y se reconoce para los primeros un papel en la nueva administración romana (García Roselló, Martín y Cela, 2000: 39-41). No obstante, a tenor de las evidencias epigráficas de grafitos ibéricos en ambos yacimientos, abrumadoramente mayoritarias, se ha cuestionado el papel de la presencia itálica para encuadrarlo en un esquema que responde al de unas élites locales "fuertemente influenciadas por el estilo de vida y la cultura itálica" (Sinner y Ferrer, 2016: 219).

Añadiremos, también, la propuesta de identificación del Puig del Castell con la ciudad de Lauro, que acuñó monedas ibéricas con la leyenda en ibérico entre $150 \mathrm{y}$ 90 a. C. (Guàrdia, 2016). La base de esta argumentación se ha centrado en la correspondencia toponímica de Lauro con la cercana Llerona -a $5 \mathrm{~km}$ del yacimiento-; los testimonios de las fuentes escritas, que nos hablan de una ciudad de Lauro que produce vinos de calidad, y la existencia de diversos tituli picti que mencionan al vino de Lauro pintados sobre ánforas de producción layetana, algunas de las cuales se ha podido confirmar su producción en la zona de Lauro; la existencia del cercano Tesoro de Cànoves, a solo $3 \mathrm{~km}$ del yacimiento, la composición del cual está formada mayoritariamente con monedas de esta misma ceca; la dispersión de las monedas de Lauro, que cierran un área cercana al yacimiento, en el cual la mayoría de monedas recuperadas pertenecen a la ceca. Todos estos elementos son los que cierran el círculo sobre una ciudad ibérica que, en su fase republicana, acabaría desarrollando el poder político y administrativo necesario para devenir centro emisor de moneda.

Todo ello apunta a un yacimiento ibérico con las características necesarias para haber albergado un contingente itálico o un sector de población

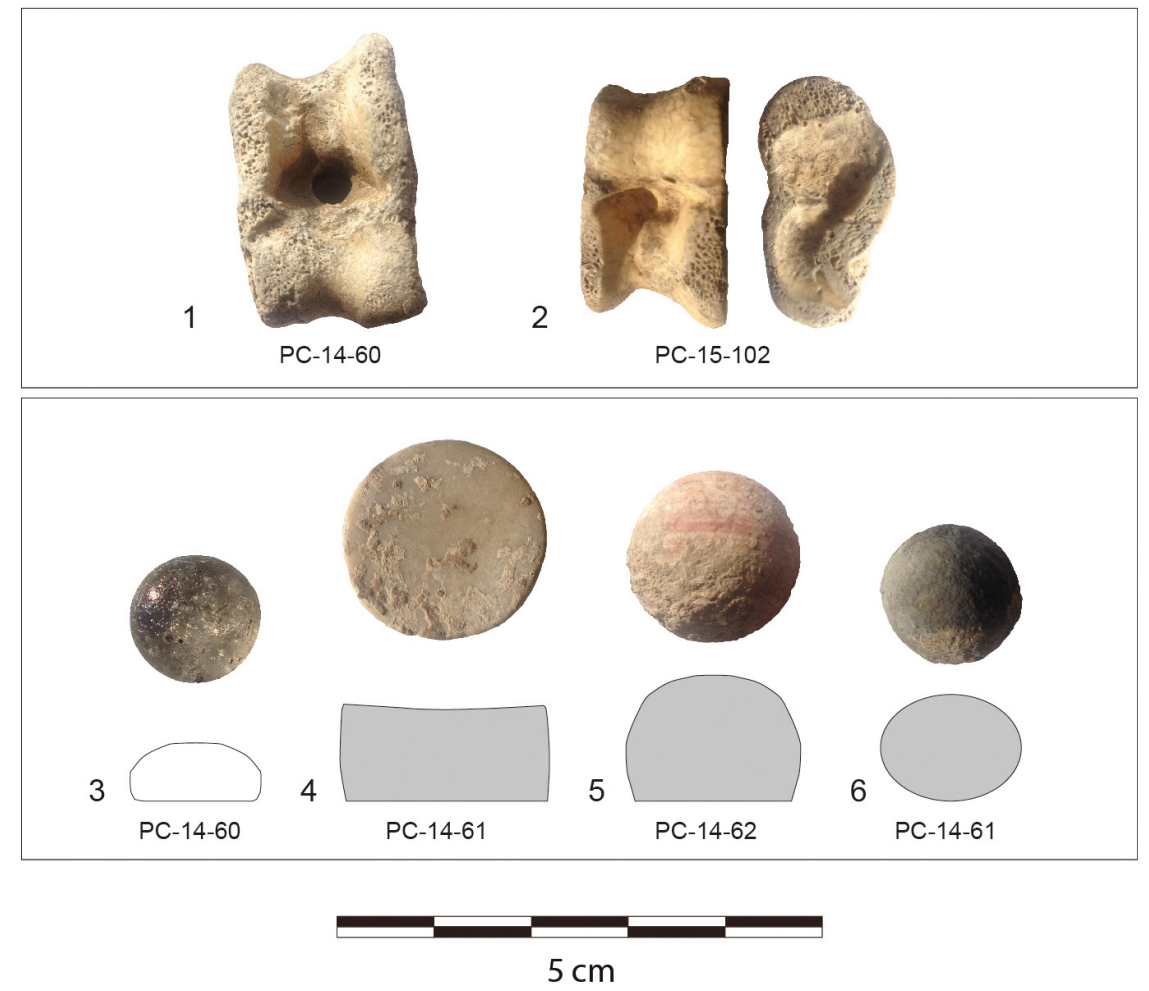

FIG. 8. Fichas de época republicana del Puig del Castell de Samalús: 1) astrágalo perforado; 2) astrágalo con caras laterales modificadas; 3) ficha de pasta de vidrio; 4-6) fichas liticas. Las fichas 4, 5 y 6 proceden del mismo recinto que la tessera GVLO (Sector 1). 
romanizado capaz de entender y participar del juego en el que eran necesarias las tesserae lusoriae. Sobre cuál sería la naturaleza de este grupo no podemos olvidar que otro tipo de juegos, con tableros y dados, se han asociado a menudo con contextos militares (Purcell, 2004: 197). En este sentido es relevante la ubicación precisa de la tessera GVLO, puesto que se recuperó en un recinto de cariz defensivo anejo a la muralla. Aunque no se puede certificar que el uso $-y$ su posterior pérdida- deban quedar circunscritos al espacio donde se ha encontrado, el mero hecho de encontrar esta ficha en un contexto de una fortificación desprende múltiples lecturas.

En los niveles republicanos del yacimiento documentados a día de hoy, todos ellos asociados a estructuras defensivas como la muralla, el interior de dos torres defensivas o el mismo recinto expuesto adosado a la entrada, también se han recuperado otras muestras de juego como diversos calculi o numerosos astrágalos -algunos modificados para regularizar sus caras, otros con agujeros de suspensión(Fig. 8). Esta asociación de registros arqueológicos en los que aparecen distintas evidencias de juego sumadas a estructuras defensivas se ha argüido en otras ocasiones para justificar el juego entre los soldados, que dispondrían de tiempo de ocio que ocupar una vez realizadas sus obligaciones (Carretero, 1998). Esta asociación de tesserae lusoriae con numerosas fichas de juego ha sido constatada en otras ocasiones, como en el citado caso de Perugia donde aparecieron cerca de 800 calculi de pasta de vidrio y diversos guijarros (algunos grabados) interpretados como fichas (Brizio y Gamurrini, 1887; Casagrande, 2012). Volviendo a la analogía con el caso de Cabrera de Mar, se ha planteado igualmente que la construcción del nuevo complejo a los pies de $\mathrm{Bu}$ rriac sugiere que el carácter de los nuevos habitantes itálicos sería militar, con una función de control y explotación del territorio (Olesti, 2000: 67).

\section{Conclusiones}

La localización de la tessera lusoria en las excavaciones arqueológicas en el yacimiento ibérico layetano del Puig del Castell -antigua Lauro- nos ha permitido profundizar en el papel que el asentamiento pudo tener en su fase republicana. La lectura del objeto nos permite teorizar sobre las características del grupo humano que la emplearía en el juego, especulando sobre su procedencia y carácter.

Una ficha, por ella misma, difícilmente nos trazará un esbozo de la situación, pero, acompañada de la interpretación del contexto, puede ayudarnos a matizar su significado. Hemos visto que, desde su ubicación precisa, un recinto de carácter defensivo, sumado a la potente fase de reorganización de las estructuras defensivas del poblado y a la construcción de una villa en el pie del oppidum en este momento, ayudan a calibrar la magnitud de su alcance. Aún no estamos en condiciones de catalogar con certidumbre la etiología de los que emplearon y perdieron la ficha de juego, en el marco de un poblado indígena. En el transcurso de las siguientes campañas de investigación arqueológica cabrá acotar el papel que esta ocupación tuvo, desde su entidad hasta su filiación.

La topografía de los hallazgos, tanto macrocomo microespacialmente, debe revelarse como una fuente de información que permita profundizar en la producción, difusión e interpretación del fenómeno de las tesserae lusoriae. Las lecturas que se derivan tanto de la tabla con la recopilación de hallazgos (Fig. 5), como del mapa de dispersión (Fig. 6), han de ir incrementando el grado de conocimiento que tenemos sobre la cuestión.

Esperamos que este nuevo testimonio, junto con todos los argumentos expuestos, ayude a profundizar en la comprensión del significado de las tesserae lusoriae.

\section{Bibliografía}

Abascal, J. M. (2012): "Cinco inscripciones del sur del conventus Carthaginensis (Hispania Citerior)”, Zeitschrift für Papyrologie und Epigraphik, 183, pp. 277-281. $\mathrm{AE}=$ Année Épigraphique

Almagro Basch, M. (1952): Las inscripciones ampuritanas, griegas, ibéricas y latinas. Barcelona.

Aquilué, X. y Pardo, J. (1990): "La vil.la romana de Can Martí (Samalús, Vallès Oriental)”, Cypsela, viII, pp. 87-100. 
BAlil, A. (1987): "Tesserae lusoriae de Ampurias". En Homenaje a D. Fletcher. Archivo de Prehistoria Levantina, 17 , pp. 331-336.

Banducci, M. (2015): "Tessera Lusoria from Gabii and the afterlife of roman gambling", Herom, Journal of Hellenistic and Roman Material Culture, 4.2. Leuven: LuP, pp. 199-221.

Baratta, G. (2014): "Le tesserae lusoriae delle Isole Baleari”. En Ferrando, C. y Costa, B. (eds.): In amicitia. Miscel.lània d'estudis en homenatge a Jordi $H$. Fernández, XIII. Ibiza, pp. 69-74.

Baratta, G. (2015): "Una tessera lusoria iscritta rinvenuta a Ruscino (Château-Roussillon, Perpignan, France)", Sylloge Epigraphica Barcinonensis, xIII, pp. 195-200.

Brizio, E. y Gamurrini, G. F. (1887): "Perugia. Tombe etrusche scoperte nel Cimitero. Nota del R. Commissario comm. G.F. Gamurrini, intorno alle tessere iscritte di sopra accennate", Notizie degli Scavi di Antichità, 1887, Roma, pp. 391-398.

Campagna, L. (1995): "Cisterne e buca di scarico di età repubblicana a Vaste (LE), Scavi di Fondo S. Antonio", Studi di Antichità, 8 (2), pp. 215-288.

Carreras, C.; Martín, A.; Pera, J. y Rodrigo, E. (2016): "Las ánforas de Brindisi en la Hispania Citerior. Pautas de distribución y consumo", Saguntum, 48, pp. 103-121.

Carretero, S. (1998): "El ludus latrunculorum, un juego de estrategia practicado por los equites del Ala II Flavia", Boletín del Seminario de Estudios de Arte y Arqueología, 64, pp. 117-140.

Carru, D. y Tallah, L. (2015): Vaucluse. Avignon, Carpentras, Cavaillon. Carte Archéologique de la Gaule, 84-4. Paris.

Casagrande, M. (2012): "Le sortes di Peruggia". En Piranomonte, M. y Simón, F. M. (eds.): Contesti Magici/Contextos Mágicos (Atti del Convegno Internazionale). Roma, pp. 247-252.

Cecchini, N. (2015): “Tessere parallelepipede". En Lambrugo, C. y Slavazzi, F. (eds.): I materiali della collezione archeologica "Giulio Sambon" di Milano. 1. Tra alea $e$ agòn: giochi di abilità e di azzardo. Firenze, pp. 67-70.

Cecchini, N.; Bianchi, Ch. y Diani, M. G. (2015): "Le scoperte di Cremona". En Lambrugo, C. y SlavAZZI, F. (eds.): I materiali della Collezione Archeologica "Giulio Sambon" di Milano. 1. Tra alea $e$ agòn: giochi di abilità e di azzardo. Firenze, pp. 121-126.

$C I L=$ Corpus Inscriptionum Latinarum

Colivicchi, F. (2007): Materiali in alabastro, vetro, avorio, osso, uova di struzzo. Materiali del Museo Archeologico Nazionale di Tarquinia, xvi. Roma.
CoRell, J. (2002): Inscripcions romanes al País Valencià, I: Saguntum i el seu territori. Valencia: Univ. de Valencia. Crawford, M. H. (2002): “Tribus, tessères et régions", Comptes rendus des séances de l'Académie des Inscriptions et Belles-Lettres, 146è année, 4, pp. 1125-1136.

De Felice, E. (1994): Larinum. Col. Forma Italiae, Serie I, 36. Firenze.

De Nino, A. (1886): "Regione iv (Samnium et Sabina). viII Pentima”, Notizie degli Scavi di Antichità, 1886, pp. 421-422.

De Palma, G.; Facchin, G. y Taffetani, C. (2011): "Prime indagini nell'area retrostante il Tempio C", Materiali per Populonia, 10, pp. 113-123.

Deonna, W. (1938): Exploration archéologique de Délos. 18, Le mobilier délien. Paris.

Fabre, G.; Mayer, M. y RodÀ, I. (2002): Inscriptions romaines de Catalogne. V: Suppléments aux volumes I-IV et instrumentum inscriptum. Paris.

Finati, G. B. (1843): Le Musée Royal-Bourbon. Napoli: Imprimerie Virgilio.

Franchi dell'Orto, L. (1994): Pompeji wiederentdeckt: Antikenmuseum Basel und Sammlung Ludwig, 19. März - 26. Juni 1994. Roma: L'Erma di Bretschneider.

Gamurrini, G. F. (1887) = Brizio, E. y Gamurrini, G. F. (1887).

Garcia Roselló, J.; Martín, A. y Cela, X. (2000): "Nuevas aportaciones sobre la romanización en el territorio de Iluro (Hispania Tarraconensis)", Empúries, 52, pp. 29-54.

GuÀrdiA, M. (2015): “A les portes de Lauro: el poblat ibèric del Puig del Castell de Samalús (Cànoves i Samalús)", Ponències, Revista del Centre d'Estudis de Granollers, 19, pp. 51-86.

Guàrdia, M. (2016): "Lauro y el poblado ibérico del Puig del Castell de Samalús (Cànoves i Samalús, Barcelona), hacia una nueva propuesta de la localización de la ceca". En Actas XV Congreso Nacional de Numismática (Madrid, 2014). Madrid, pp. 863-886.

Gusman, P. (1900): Pompei. The city, its life and art. London: W. Heinemann Ed.

Helbig, W. (1877): "Scavi di Corneto", Bullettino dell'Instituto di Correspondenza Archeologica, vI, pp. 113-118.

Huelsen, Ch. (1896): "Miscellanea epigrafica", Mittheilungen des Kaiserlich Deutschen Archaeologischen Instituts, Roemische Abtheilung, XI, pp. 227-257.

IsleR, H. P. (2003): “Monte Iato: Scavi 1998-2000”. En Atti Quarte Giornate Internazionali di Studi sull'Area Elima (Erice, 2000). Pisa, t. II, pp. 827-851.

IRC V = FABRE, G.; MAYER, M. y RodÀ, I. (2002).

Le Blant, E. (1888): "Lettre du directeur de l'École française de Rome", Comptes rendus des séances de 
l'Académie des Inscriptions et Belles-Lettres, $32^{\mathrm{e}}$ année, 2, pp. 103-107.

MAYer, M. y RodÀ, I. (1988): "Epigrafia", Fonaments, 7, pp. 193-263.

NSA I 877 = BRIZIO, E. y GAMURRINI, G. F. (1887).

NSA $1886=$ De Nino (1886).

Olesti, O. (2000): "Integració i transformació de les comunitats ibèriques del Maresme durant el s. II-I a. C.: un model de romanització per a la Catalunya litoral i prelitoral”, Empúries, 52, pp. 55-86.

OrSI, P. (1920): "Siracusa. Sepolcri siculi sul ciglione meridionale dell'Epipole”, Notizie degli Scavi di Antichità, XvII, pp. 303-327.

Pera, J.; Carreras, C.; Rodrigo, E.; Padrós, N.; RoMANí, N.; Ros, J. y Guitart, J. (2013): “El proceso previo a la fundación de las ciudades romanas en el NE de la Hispania Citerior: los ejemplos de Can Tacó y Puig Castellar". En IV Convegno Internazionale di Studi Veleiati. Veleia, pp. 527-544.
Purcell, N. (2004): "Literate games: Roman urban society and the game of alea". En Osborne, R. (ed.): Studies in Ancient Greek and Roman Society. Cambridge, pp. 177-205.

Rodríguez Martín, F. G. (2016): “Tesserae lusoriae en Hispania”, Zephyrus, LxxviI, pp. 207-220.

Sinner, A. G. y Ferrer, J. (2016): "Del oppidum de Burriac a las termas de Ca l'Arnau. Una aproximación a la lengua y a la identidad de los habitantes de Ilduro (Cabrera de Mar, Barcelona)", Archivo Español de Arqueología, 89, pp. 193-223.

Stelluti, N. (1997): Epigrafi di Larino e della Bassa Frentania: Il repertorio. Campobasso: Palladino Ed.

Veny, C. (1965): Corpus de las inscripciones baleáricas hasta la dominación árabe. Madrid.

ZeI, C. (1921): "v. Ferento (Viterbo). Scoperta di tombe di età repubblicana", Notizie degli Scavi di Antichità, XVIII, pp. 215-228. 